\title{
Efficient solution for accelerating very high intensity beams in the low and medium energy regime
}

\author{
Chuan Zhang $\odot,{ }^{1, *}$ Holger Podlech, ${ }^{2}$ Ulrich Ratzinger, ${ }^{2}$ and Rudolf Tiede ${ }^{2}$ \\ ${ }^{1}$ GSI Helmholtz Center for Heavy Ion Research, Planckstr. 1, 64291 Darmstadt, Germany \\ ${ }^{2}$ Institute for Applied Physics, Goethe University, Max-von-Laue-Str. 1, 60438 Frankfurt a. M., Germany
}

(Received 10 April 2019; published 4 October 2019)

\begin{abstract}
Taking advantage of the $0^{\circ}$ synchronous phase, the kombinierte null grad struktur (KONUS) beam dynamics strategy enables long accelerating sections with lens-free slim drift tubes in the low and medium energy regime. It has successfully realized worldwide many normal-conducting H-type linacs with compact layouts and good beam performance. In this paper, a further development of this solution, i.e., to combine the KONUS dynamics with the recently developed superconducting $\mathrm{CH}$ structure for accelerating very high intensity beams, is presented. The efficiency of the new solution has been shown by systematic design studies performed for a $150 \mathrm{~mA}, 6 \mathrm{MW}$ deuteron linac.
\end{abstract}

DOI: 10.1103/PhysRevAccelBeams.22.100101

\section{INTRODUCTION}

For the production of various useful high intensity secondary beams, e.g., neutrons, the development of megawatt-class linear accelerators has become very attractive in the past several decades. Serving as drivers of large-scale facilities for modern scientific and civil applications, this kind of linac usually needs to deliver very powerful light ion beams, e.g., $\mathrm{H}^{+}, \mathrm{H}^{-}$, or $\mathrm{D}^{+}$, to bombard a certain target. Having been put into operation already in the early 1970s, the Los Alamos Neutron Science Center (LANSCE) linac [1], formerly known as Los Alamos Meson Physics Facility, can provide protons with an average beam power up to $\sim 0.8 \mathrm{MW}$. Different from the full normal-conducting (NC) LANSCE linac, the $\sim 1.4$ MW Spallation Neutron Source (SNS) linac [2] built in 2006 started to employ superconducting (SC) radio-frequency (rf) technology for beam acceleration in the high $\beta$ region. So far, many modern facilities based on this kind of high power driver linac (HPDL) have been realized, e.g., Japan Proton Accelerator Research Complex [3], or proposed, e.g., Multi-purpose Hybrid Research Reactor for High-tech Applications (MYRRHA) [4], worldwide, with the tendency to start the SC part already in the low and medium $\beta$ region.

\footnotetext{
*.zhang@gsi.de
}

Published by the American Physical Society under the terms of the Creative Commons Attribution 4.0 International license. Further distribution of this work must maintain attribution to the author(s) and the published article's title, journal citation, and DOI.
The average beam power is given by Eq. (1):

$$
\begin{aligned}
\text { Average beam power }[\mathrm{MW}]= & \text { voltage gain }[\mathrm{MV}] \\
& \times \text { beam current }[\mathrm{A}] \\
& \times \text { beam duty factor. }
\end{aligned}
$$

To reach a beam power on the order of megawatts, there are typically the following several ways to combine these three factors for a modern HPDL machine: (i) using high voltage gain, a modest current, and a low duty factor, e.g., LANSCE and SNS; (ii) using high voltage gain, a low current, and continuous wave (CW) mode, e.g., MYRRHA and Proton Improvement Plan-II [5]; and (iii) using low voltage gain, a very high current, and CW mode, e.g., LowEnergy Demonstration Accelerator [6] and International Fusion Materials Irradiation Facility (IFMIF) [7].

Figure 1 shows a schematic layout of a modern largescale HPDL. It can be roughly divided into the following three parts: (i) very low $\beta(0.01-0.1)$ part-the NC radiofrequency quadrupole (RFQ) accelerator is a standard injector structure; (ii) high $\beta(>0.5)$ part-the SC elliptical cavity is dominating in this area; (iii) low and medium $\beta(0.1-0.5)$ part—different solutions based on various NC and SC drift-tube linac (DTL) structures, e.g., Alvarez-type DTL, half wave resonator (HWR), and quarter wave resonator (QWR), can be used.

For proton and ion linacs, the classic beam dynamics strategy applies negative synchronous phases, typically $-30^{\circ}$ to $-40^{\circ}$, to the accelerating cells. It provides the beam longitudinal stability but at the same time rf defocusing effects in the transverse planes. In the case of high currents, the space charge effects are especially pronounced in the low and medium energy regime. 


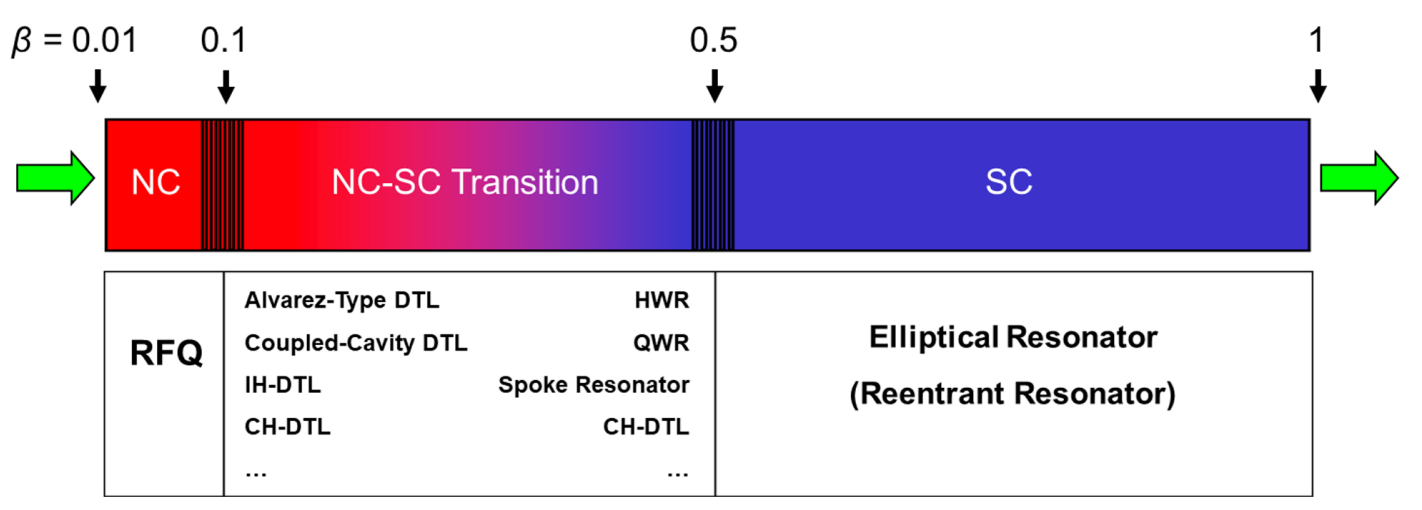

FIG. 1. Typical layout of a modern large-scale HPDL with different $\mathrm{rf}$ structures for different $\beta$ ranges.
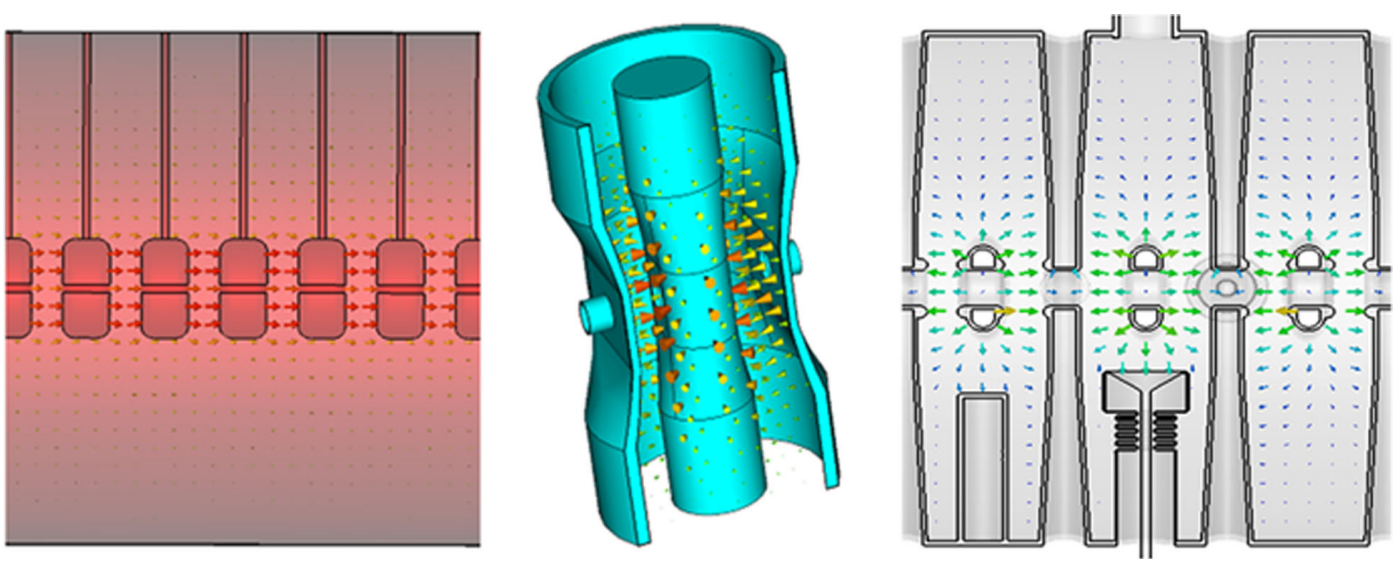

FIG. 2. Alvarez-type (left), HWR (middle), and H-type (right) structures with electric fields.
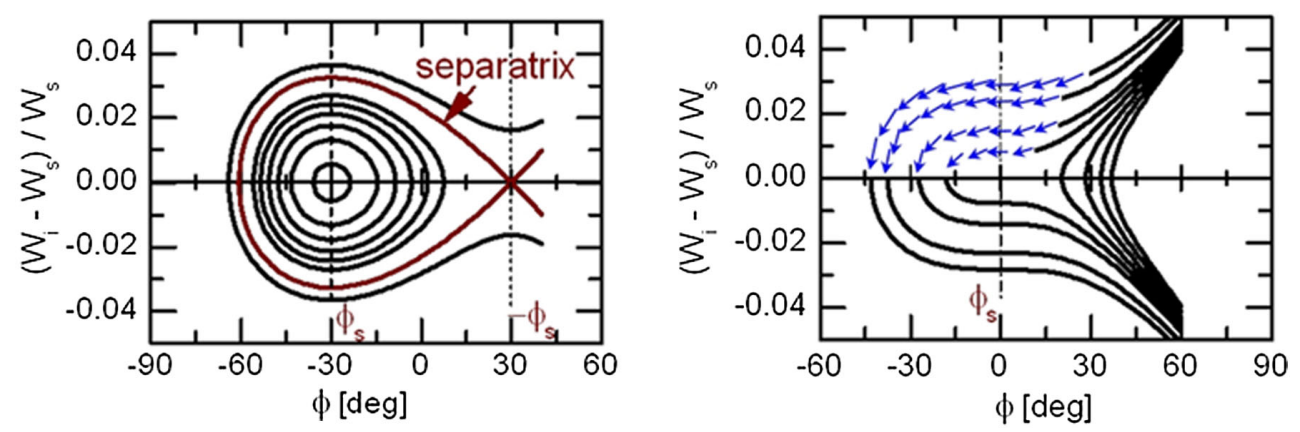

FIG. 3. Schematic plot for particle trajectories in the longitudinal phase space at $\phi_{s}=-30^{\circ}$ (left) or $\phi_{s}=0^{\circ}$ (right).

Based on the classic negative-synchronous-phase beam dynamics strategy, two well-established solutions for the conventional low and medium energy linacs are as follows: (i) using long (multicell, hereafter referred to as $>3$ cells) $\mathrm{NC}$ structures, e.g., Alvarez-type DTL with integrated magnetic lenses inside drift tubes, and (ii) using short (typically 2-3 cells per cavity) SC structures, e.g., HWR or QWR with independent lenses outside of the cavities (see Fig. 2).

For both of them, a relatively high number of magnets are required to provide sufficient transverse focusing.
Different from the above-mentioned two solutions, a special beam dynamics strategy, so-called KONUS ("combined $0^{\circ}$ structure" translated from German "kombinierte null grad struktur") [8,9] applies the $0^{\circ}$ synchronous phase instead of negative synchronous phases to the reference particle in most accelerating cells. The purpose is to overcome the transverse defocusing effects by increasing the acceleration efficiency at $\varphi_{s}=0^{\circ}$ so that the use of long accelerating sections with lens-free slim drift tubes becomes feasible. 
TABLE I. An overview of KONUS-based H-type DTLs.

\begin{tabular}{lcccccc}
\hline \hline Linac & Resonator & Ion & $f[\mathrm{MHz}]$ & $I[\mathrm{~mA}]$ & $\beta$ & Status \\
\hline GSI HLI & $\mathrm{IH}$ & $A / q \leq 9.5$ & 108.408 & 0.1 & $0.025-0.055$ & In operation \\
GSI HSI & IH & $A / q \leq 65$ & 36.136 & $\leq 0.25 *(A / q)$ & $0.016-0.055$ & In operation \\
CERN Linac 3 & IH & ${ }^{208} \mathrm{~Pb}^{25+},{ }^{208} \mathrm{~Pb}^{27+}$ & $101.28,202.56$ & 0.1 & $0.023-0.094$ & In operation \\
CERN REX-ISOLDE & $\mathrm{IH}$ & Radioactive ions $A / q \leq 4.5$ & 101.28 & 0.1 & $0.025-0.050$ & In operation \\
HICAT & $\mathrm{IH}$ & ${ }^{12} \mathrm{C}^{4+}, \mathrm{H}^{+}$ & 216.816 & $>0.12,1.2$ & $0.029-0.121$ & In operation \\
BNL new EBIS & $\mathrm{IH}$ & $A / q \leq 6.25$ & 100.625 & $1.7-2.0$ & $0.025-0.065$ & In operation \\
FRANZ & $\mathrm{IH}$ & $\mathrm{H}^{+}$ & 175 & $50-150$ & $0.039-0.063$ Waiting for operation \\
GSI p-Linac & $\mathrm{CH}$ & $\mathrm{H}^{+}$ & 325 & 70 & $0.080-0.361$ Under construction \\
\hline \hline
\end{tabular}

However, the separatrix that exists at negative synchronous phases, e.g., $-30^{\circ}$, will shrink to zero at $\varphi_{s}=0^{\circ}$ (see Fig. 3). To solve this problem, KONUS uses only the area marked by blue arrows in the longitudinal phase space, which means that the synchronous particle defining the geometrical layout of the drift tube array (with the synchronous energy $W_{s}$ ) and the bunch center (BC) particle (with the real energy $W_{\mathrm{BC}}$ ) are decoupled. The energy difference at the beginning of a $0^{\circ}$ section is realized by setting $W_{s}<W_{\mathrm{BC}}$, while the phase difference is obtained by adjusting the tank rf phase at the entrance of each cavity or by fitting the geometrical length of the transition cell inside a cavity. In short, the beam is injected into a $0^{\circ}$ section asynchronously with a surplus in bunch energy and with a proper phase slip against the synchronous particle.

This concept was first applied in combination with an interdigital H-type (IH) structure for the heavy ion postaccelerator at the Munich tandem laboratory [10]. Table I shows a list of existing and planned KONUS-based H-type

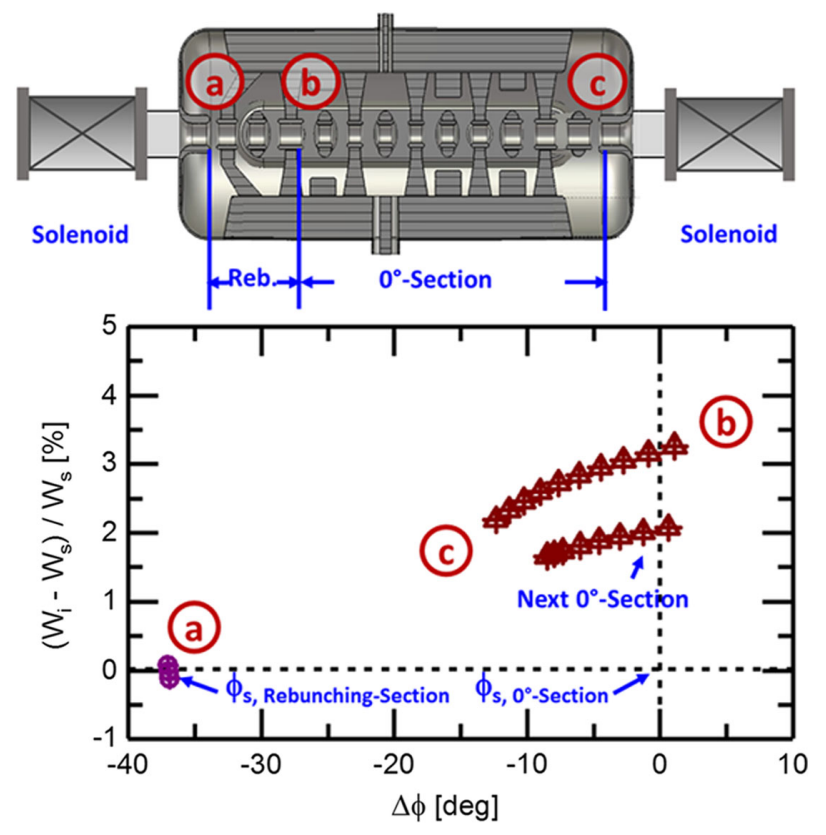

FIG. 4. A combination of KONUS and SC CH for accelerating very high intensity beams.
DTLs worldwide. It can be seen that the development of this kind of machine is not only toward higher $\beta$ but also toward a higher current. So far, all realized and to-be-realized KONUS machines are normal conducting accelerators.

For very high intensities, a high accelerating gradient is helpful to overcome serious space charge effects quickly, and it can be achieved with SC accelerating structures much more easily. Taking advantage of the feature of the long lens-free sections allowed by KONUS, the superconducting crossbar H-type $(\mathrm{CH})$ structure is a good candidate of a multicell, $\mathrm{SC}$ accelerating structure in the low and medium $\beta$ region [11].

This study is dedicated to investigating a solution using a combination of the KONUS dynamics with the recently developed SC $\mathrm{CH}$ structure for accelerating very high intensity beams in the low and medium $\beta$ range. In this solution, most of the beam acceleration will be done by the SC CH structure mainly working at $\varphi_{s}=0^{\circ}$ and, if necessary, including a short rebunching section working at negative synchronous phases typically $\varphi_{s}=-35^{\circ}$ for improving the phase stability. The summed up transverse defocusing effects from both the space charge and the rf field can be compensated by using external solenoid lenses. The proposed solution is shown in Fig. 4 schematically.

\section{KONUS AND SC CH DESIGN FOR A 6 MW DRIFT-TUBE LINAC}

To address the challenges of very high intensity and very high power beams, a $175 \mathrm{MHz}, 150 \mathrm{~mA}$, CW deuteron drift-tube linac aiming to increase $\beta$ from 0.07 to 0.20 is chosen for this study. The total beam power of this DTL is considerably high, about $6 \mathrm{MW}$. For a convenient description, this linac will be called the 6 MW DTL in the following text.

To overcome the problems with respect to safety and reliability, e.g., activation and SC quenching which can possibly be caused by beam losses, good beam quality is required for such a very high power linac. Therefore, a very careful design with conservative parameter choices and special optimization concepts has been made for the 6 MW DTL. 


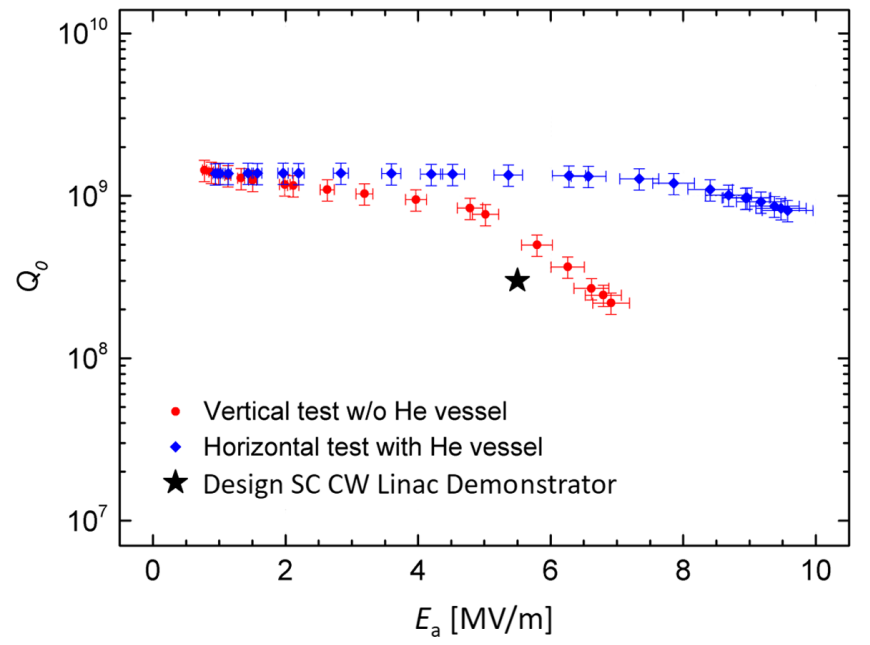

FIG. 5. rf test results of the SC CH cavity for the SC CW linac demonstrator at $4.2 \mathrm{~K}$ [16].

The considerations for the general layout of this $6 \mathrm{MW}$ DTL are the following: (i) The main beam acceleration ( $\beta=0.10-0.20$ ) will be accomplished by superconducting $\mathrm{CH}$ cavities. (ii) To be error tolerant, in front of the SC part, it is decided to add a $\mathrm{NC}$ transition section consisting of a two-cell rebuncher and an IH cavity $(\beta=0.07-0.10)$ to match the RFQ output beam well into the $\mathrm{SC} \mathrm{CH}$ cavities and to filter possible beam halo particles caused by the RFQ and the RFQ-DTL transition. (iii) Quadrupole lenses and solenoids will be used as transverse focusing elements in the NC and SC parts, respectively.

Many choices for the key parameters of its main components are based on experience learned from existing machines and real experiments.

For the NC part, the accelerating gradient $E_{a}$ of the IH cavity has been taken as $2.2 \mathrm{MV} / \mathrm{m}$, which is similar to the built CW NC IH cavities, e.g., the Frankfurt Neutron Source at Stern-Gerlach-Zentrum (FRANZ) IH [12], and much lower than the already reached $E_{a}$ values for pulsed
$\mathrm{NC}$ IH cavities, e.g., $E_{a}=3.8,6.4$, and $4.9 \mathrm{MV} / \mathrm{m}$ for the IH-1, IH-2, and IH-3 cavities of the CERN Linac3, respectively [13]. Concerning the quadrupole lenses, pole tip fields up to $B_{\max }=1.3 \mathrm{~T}$ are available with conventional technology (NC, laminated cobalt steel alloys). For this linac, quadrupole lenses with $B_{\max }=1.15 \mathrm{~T}$ have been adopted with a safety margin.

For the SC part, the key parameters of the SC CW linac demonstrator consisting of a 15-cell SC CH cavity and two SC solenoids can be taken as a good reference. In 2017, this

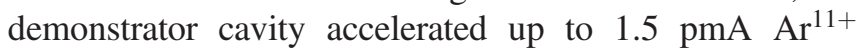
beams to the design beam energy with full transmission [14]. That is the first time for $\mathrm{CH}$ cavities to be tested with a beam. Though the demonstrator is not based on KONUS but another kind of special beam dynamics concept, the so-called equidistant multigap structure [15], the hardware performance proven by its experiments applies to KONUS lattices as well.

Figure 5 shows the rf test results of the demonstrator cavity at $4.2 \mathrm{~K}$ in the vertical orientation without a helium vessel and in the horizontal orientation with a helium vessel, respectively [16]. The horizontal test was done after the vertical test, and, in between, the cavity had been improved with an additional high pressure rinsing. It can be seen that, although the design accelerating gradient of this demonstrator cavity is $5.5 \mathrm{MV} / \mathrm{m}$, a maximum $E_{\mathrm{a}}=$ $9.6 \mathrm{MV} / \mathrm{m}$ (the corresponding peak magnetic field $B_{p}=$ $55 \mathrm{mT})$ at $Q_{0}=8.14 \times 10^{8}$ can be achieved. Also, the two solenoids with $B_{\max }=9.3 \mathrm{~T}$ have been successfully tested at $4.2 \mathrm{~K}$ [16]. In general, it is advisable to be more conservative using superconducting $\mathrm{CH}$ cavities. Because the $6 \mathrm{MW}$ DTL requires a large voltage gain by many multicell cavities and every cavity must reach its design gradient, more conservative choices, $E_{\mathrm{a}}=\sim 5 \mathrm{MV} / \mathrm{m}$ and $B_{\max }=\sim 7 \mathrm{~T}$, have been chosen for the SC CH cavities and the SC solenoids, respectively.

For each SC $\mathrm{CH}$ cavity, two rf power couplers are foreseen, and each of them needs to feed the cavity with $\mathrm{rf}$
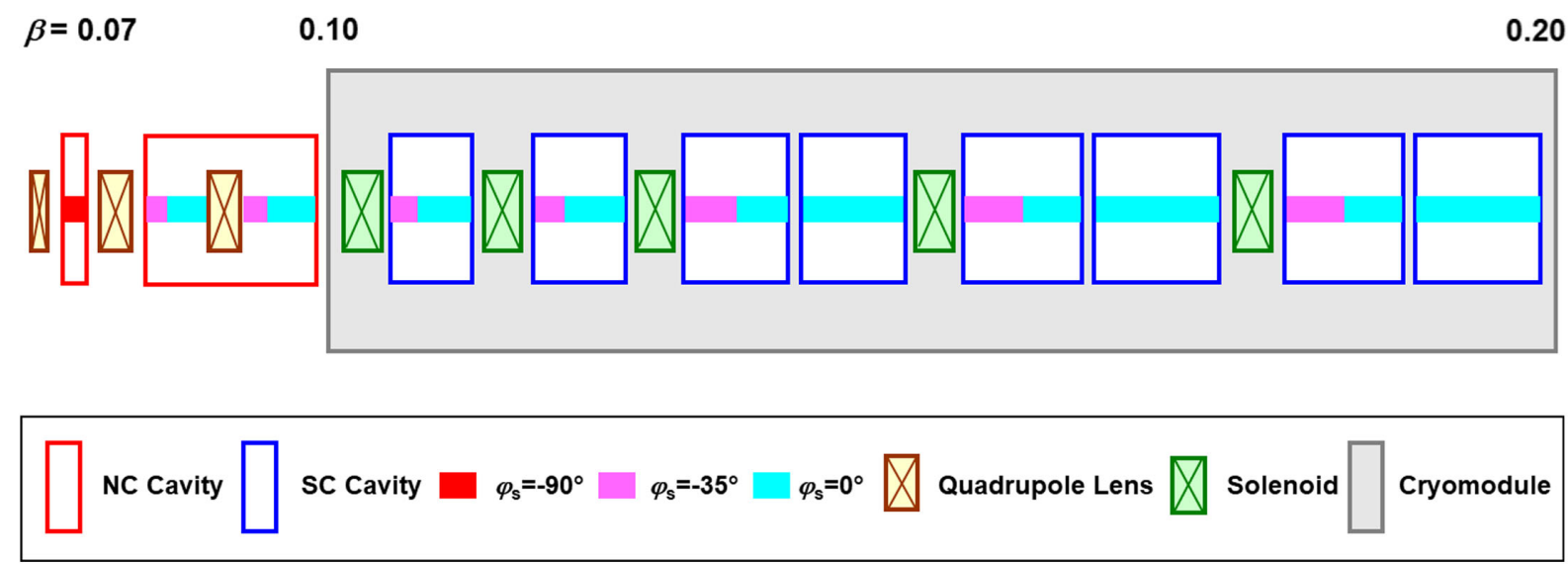

FIG. 6. Schematic layout of the 12 -m-long $6 \mathrm{MW} \mathrm{DTL.}$ 
TABLE II. Main design parameters of the $6 \mathrm{MW}$ DTL.

\begin{tabular}{lcc}
\hline \hline Parameter & NC part & SC part \\
\hline Frequency [MHz] & 175 & 175 \\
Beam intensity [mA] & 150 & 150 \\
Beam velocity $\beta$ & $0.07-0.10$ & $0.10-0.20$ \\
Number of cavities & 2 & 8 \\
Accelerating gradient $E_{a}[\mathrm{MV} / \mathrm{m}]$ & 2.2 & $\sim 5.0$ \\
Number of accelerating cells & 22 & 54 \\
Number of cells with $\varphi_{s}=-90^{\circ}$ & 2 & 0 \\
Number of cells with $\varphi_{s}=-35^{\circ}$ & 5 & 15 \\
Number of cells with $\varphi_{s}=0^{\circ}$ & 15 & 39 \\
Maximum electric field on & $3.02-6.78$ & $7.36-11.23$ \\
$\quad$ axis [MV/m] & 3 (multiplet) & 6 (solenoid) \\
Number of lenses & 1.15 & 7 \\
Magnetic field $B_{\max }[\mathrm{T}]$ & 2.2 & 9.5 \\
Total layout length $L_{\text {total }}[\mathrm{m}]$ &
\end{tabular}

power up to $400 \mathrm{~kW}$. At the given frequency, coaxial-type couplers are a reasonable choice. These power couplers have shown their capability to handle very high power levels in various projects [17].

For easy construction and mechanical robustness, the SC $\mathrm{CH}$ cavities of the $6 \mathrm{MW}$ DTL have been limited to be shorter than $1 \mathrm{~m}$, so they have relatively lower numbers of cells: nine cells per cavity for the first two SC CH cavities and six cells per cavity for the others, respectively. To still take advantage of the efficiency of the $0^{\circ}$ section, the so-called "super $0^{\circ}$ section" that extends a $0^{\circ}$ section over two neighboring cavities has been introduced. In Fig. 6, one can see that the SC part of the designed 6 MW DTL has totally five $0^{\circ}$ sections, among which the last three are the super ones. A summary of the detailed design parameters for the $\sim 12$-m-long $6 \mathrm{MW}$ DTL is given in Table II.

The starting conditions $\Delta \phi$ and $\Delta W$ of the bunch at the first gap of each $0^{\circ}$ section have a decisive influence on the KONUS beam dynamics. Figure 7 shows the typical

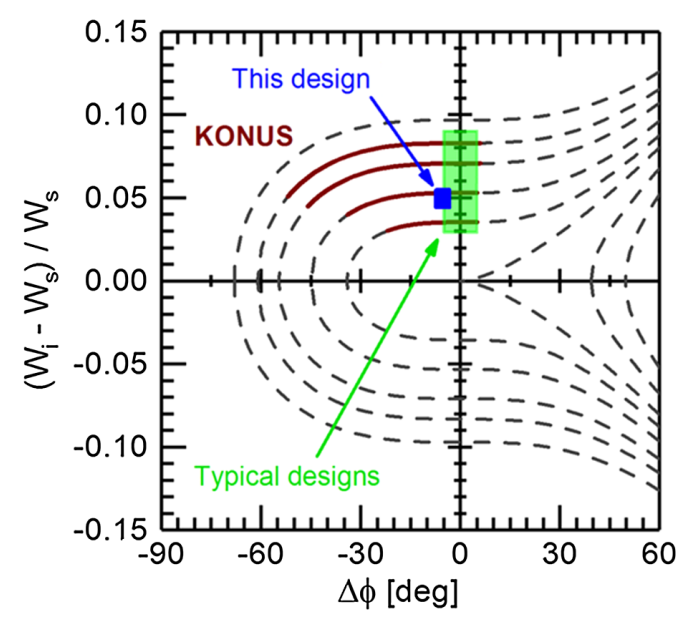

FIG. 7. Typical starting $\Delta \phi$ and $\Delta W$ for the $0^{\circ}$ sections and the choices for the $6 \mathrm{MW}$ DTL. working area used by KONUS designs: $\Delta \phi=-5^{\circ}$ to $5^{\circ}$ and $\Delta W=3 \%$ to $9 \%$. Generally speaking, (i) a more positive $\Delta \phi$ is for a relatively longer $0^{\circ}$ section, while a more negative $\Delta \phi$ is for a shorter $0^{\circ}$ section; (ii) a smaller $\Delta W$ is for a relatively lower beam energy, while a larger $\Delta W$ is for a higher beam energy. For the $6 \mathrm{MW}$ DTL, the design choices are also quite conservative: $\Delta \phi$ is around $-5^{\circ}$, and $\Delta W$ is around $5 \%$.

\section{BEAM DYNAMICS SIMULATION RESULTS}

The beam transport simulation along the 6 MW DTL has been performed with LORASR [18], a dedicated computer code for the KONUS dynamics using H-type structures. For the generation of the input distribution for the $6 \mathrm{MW}$ DTL, the CDR-RFQ design for the IFMIF project $[19,20]$ has been adopted. The $140 \mathrm{~mA} \mathrm{D}{ }^{+} \mathrm{RFQ}$ uses a waterbag-type input distribution (input beam energy, $50 \mathrm{AkeV}$; normalized rms transverse input emittance, $0.2 \pi \mathrm{mm}$-mrad). In the experiments very recently done for the IFMIF prototype linac, good emittance $(0.15 \pi \mathrm{mm}$-mrad $)$ of the $50 \mathrm{AkeV} \mathrm{D^{+ }}$ beam at extracted beam currents up to $175 \mathrm{~mA}$ was measured after the first solenoid of the low energy beam transport [21]. And it is also reported in Ref. [21] that this emittance can be maintained until the RFQ entrance, which was confirmed by the series of injector beam commissioning campaigns in 2015 and 2016.

To generate a $\sim 150 \mathrm{~mA}$ beam for the injection into the $6 \mathrm{MW}$ DTL, the input beam current of the IFMIF CDR-RFQ has been increased to $155 \mathrm{~mA}$, and accordingly a 5\% higher intervane voltage has been applied. This change raised the Kilpatrick factor from 1.68 to 1.76 and the transverse output emittance from 0.23 to $0.26 \pi \mathrm{mm}-\mathrm{mrad}$, respectively, but these values are still very comparable to those of the current reference design for the IFMIF RFQ [22]. Including $\sim 1$ million macroparticles, the simulated input distribution for the $6 \mathrm{MW}$ DTL is shown in the top graphs in Fig. 8. The phase spread is $\pm 30^{\circ}$ and larger than the ideal range, i.e., $\pm 15^{\circ}$ for the KONUS dynamics. It can be also seen in Fig. 8 that the particle distributions at the end of the 6 MW DTL are still concentrated. In the longitudinal plane, there are some small halos but within a very modest phase spread and energy spread.

As a function of the position along the 6 MW DTL, both transverse and longitudinal emittance values are plotted in Fig. 9. All curves have similar and smooth evolutions. The emittance growths are 64\%, 63\%, and $50 \%$ for the $x, y$, and longitudinal planes, respectively.

Figure 10 shows the ratios of the longitudinal and transverse emittances and phase advances along the accelerating channel, where the data labels indicate the serial numbers of the lattice periods. In LORASR, each lattice period is the accelerating section between two neighboring magnetic lenses (except the first period, which is defined 

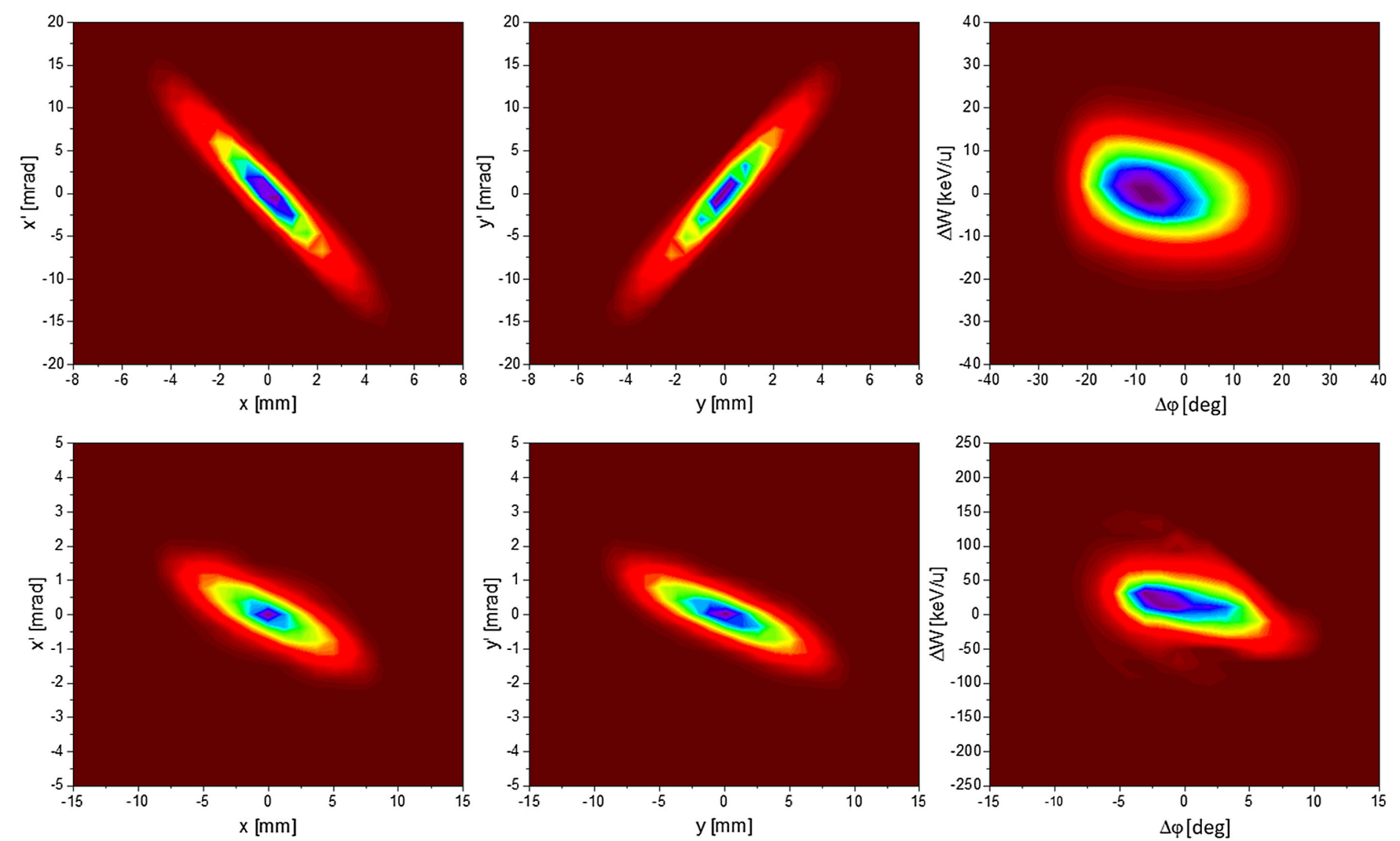

FIG. 8. Input (top graphs) and output (bottom graphs) particle distributions of the 6 MW DTL.

from the starting point to the first lens array). Each period ends behind the last lens of the corresponding array. It can be seen that the ratio of the phase advances is nearly constant along the accelerating channel, which indicates a balance between the longitudinal and transverse focusing strengths. As a result, the emittance ratio has been held relatively stable at $\sim 1.75$ throughout the linac. The small jump in the second lattice period, i.e., between the first two lenses, is because the given input phase spread is twice as large as the ideal one for KONUS, and a strong two-cell rebuncher working at $\varphi_{s}=-90^{\circ}$ is necessary there for a better longitudinal matching. Afterwards, this situation has

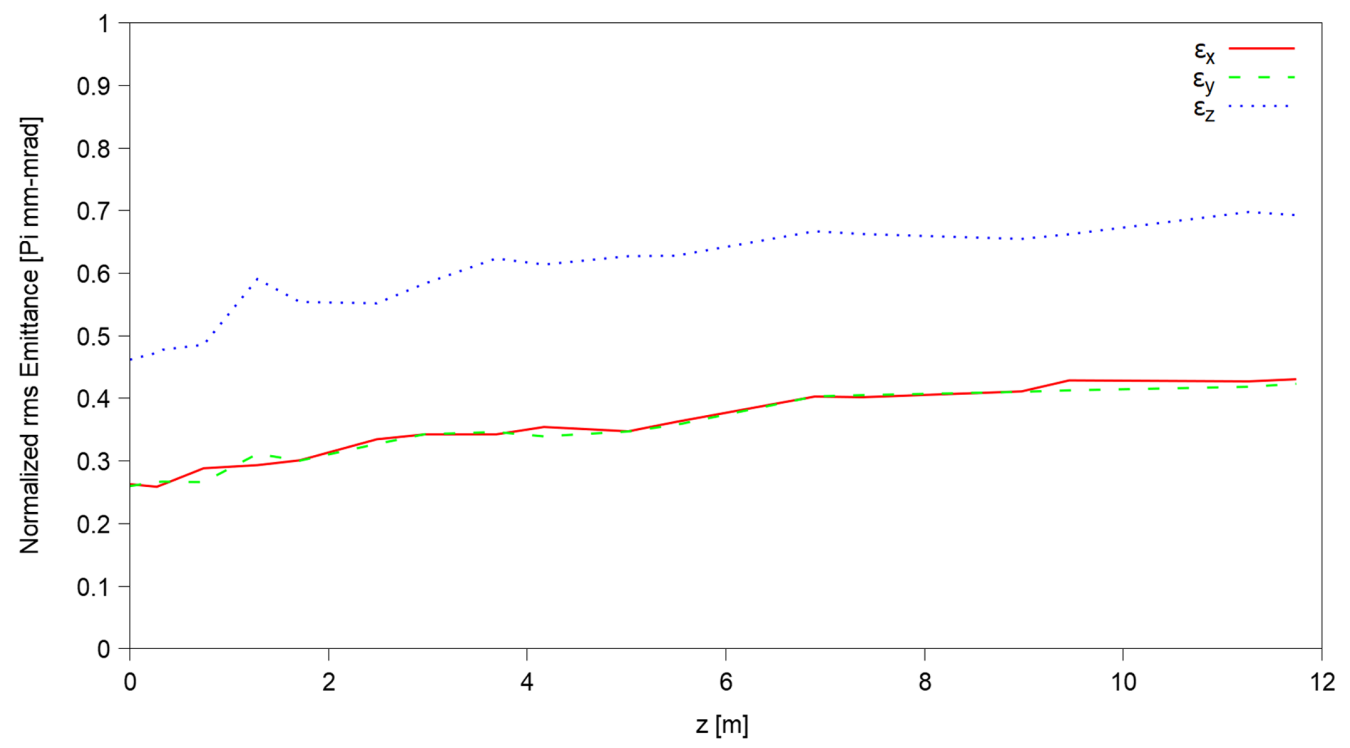

FIG. 9. Emittance evolutions along the 6 MW DTL (red, $x$ plane; green, $y$ plane; blue, longitudinal plane). 


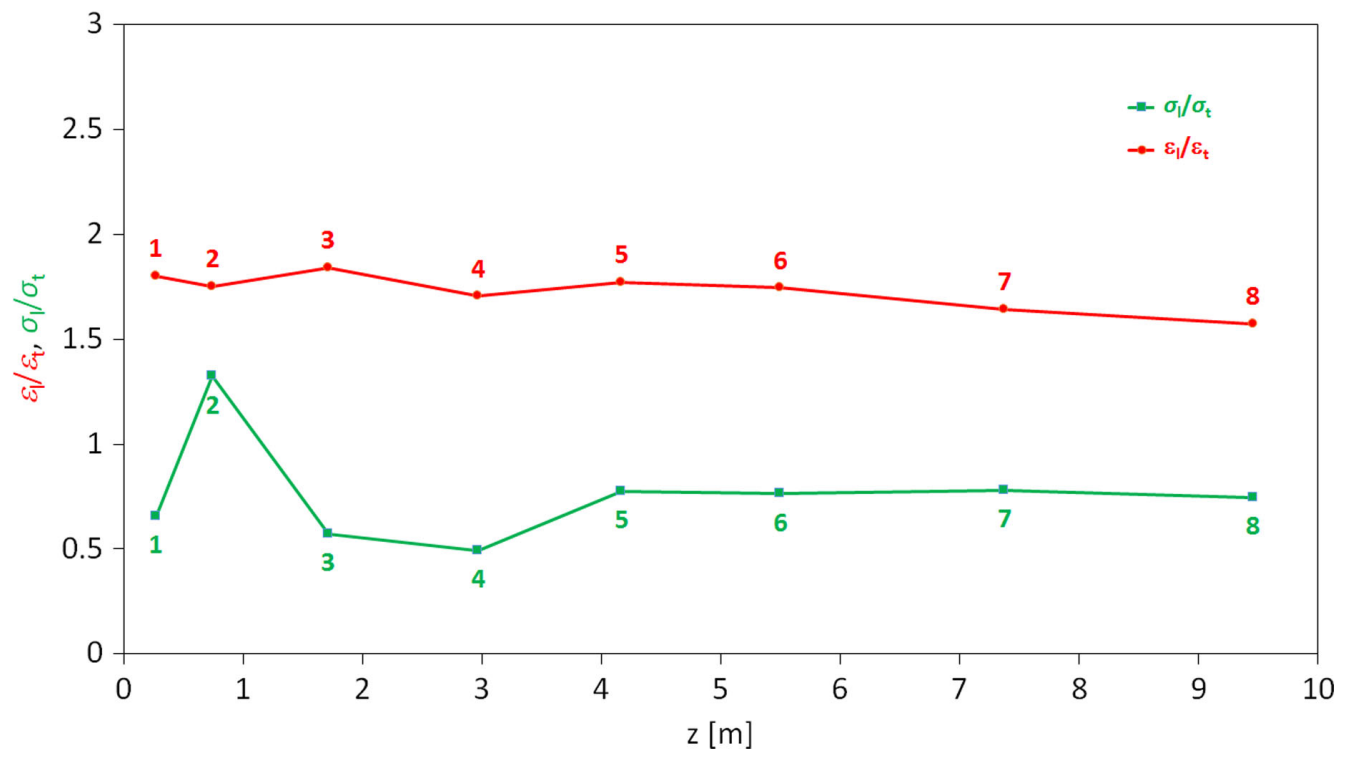

FIG. 10. Ratios of emittances and phase advances (with data labels indicating the serial numbers of the lattice periods).

been changed back to normal by the properly designed second lens.

The motions of the beam bunch centers in the seven normal and super $0^{\circ}$ sections are shown in Fig. 11, where the data labels indicate the cell numbers. Around the design working point, the starting $\Delta \phi$ and $\Delta W$ values of the $0^{\circ}$ sections range from $-4^{\circ}$ to $-6^{\circ}$ and from $4.5 \%$ to $5.8 \%$, respectively. It can be seen that all the $0^{\circ}$ sections have been ended properly at stable positions around $\varphi_{s}=-30^{\circ}$ in the longitudinal phase space.
Including all particles, the transverse and longitudinal $100 \%$ beam envelopes are shown in Figs. 12 and 13, respectively. In the transverse planes, the evolutions of the beam sizes along the DTL are very similar, especially in the SC part. The maximum beam size is $\sim \pm 16.5 \mathrm{~mm}$, which leaves the beam a safety margin to the tubes and the lenses. Besides, it can be seen from the longitudinal $100 \%$ beam envelopes that the relative energy spread and the phase spread of the beam are also well confined throughout the DTL.

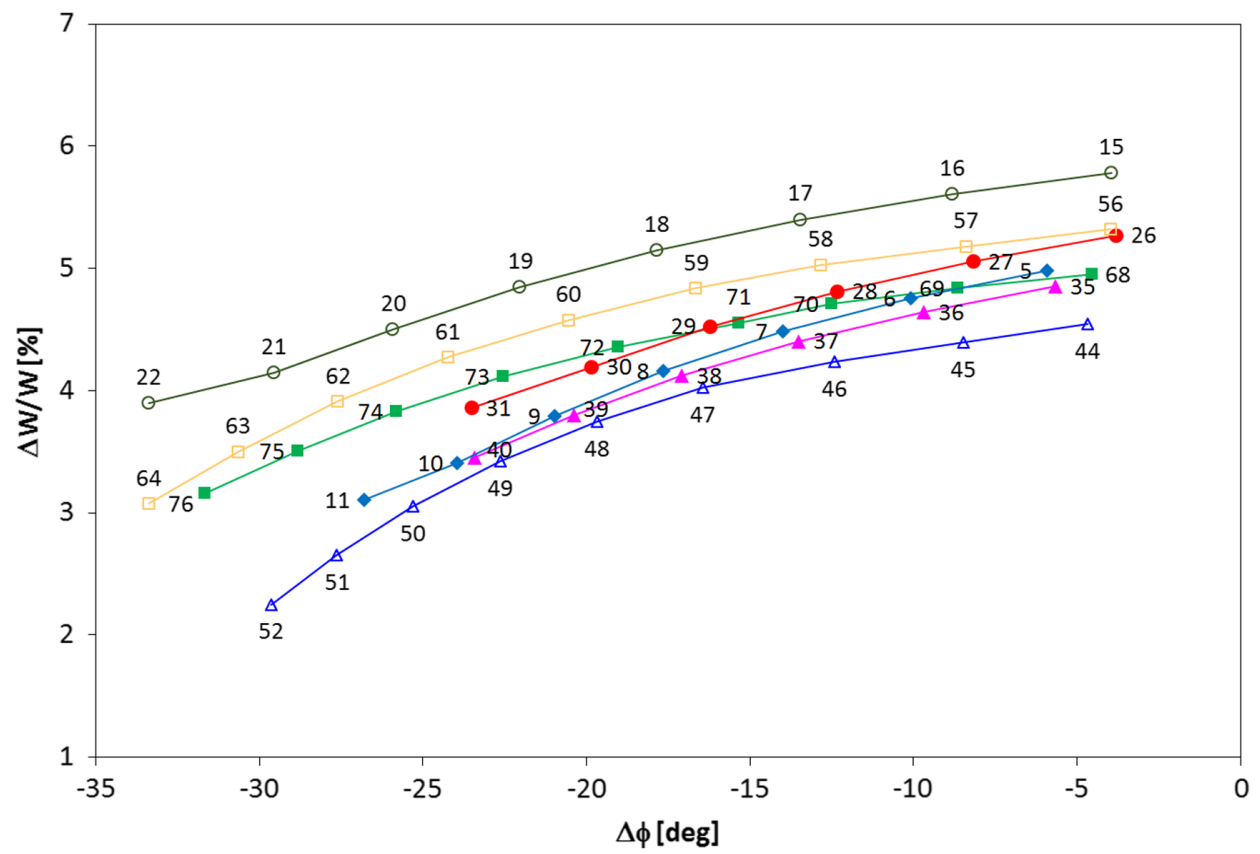

FIG. 11. Motions of beam bunch centers in the longitudinal phase space for all $\varphi_{s}=0^{\circ}$ cells (with data labels indicating the cell numbers). 


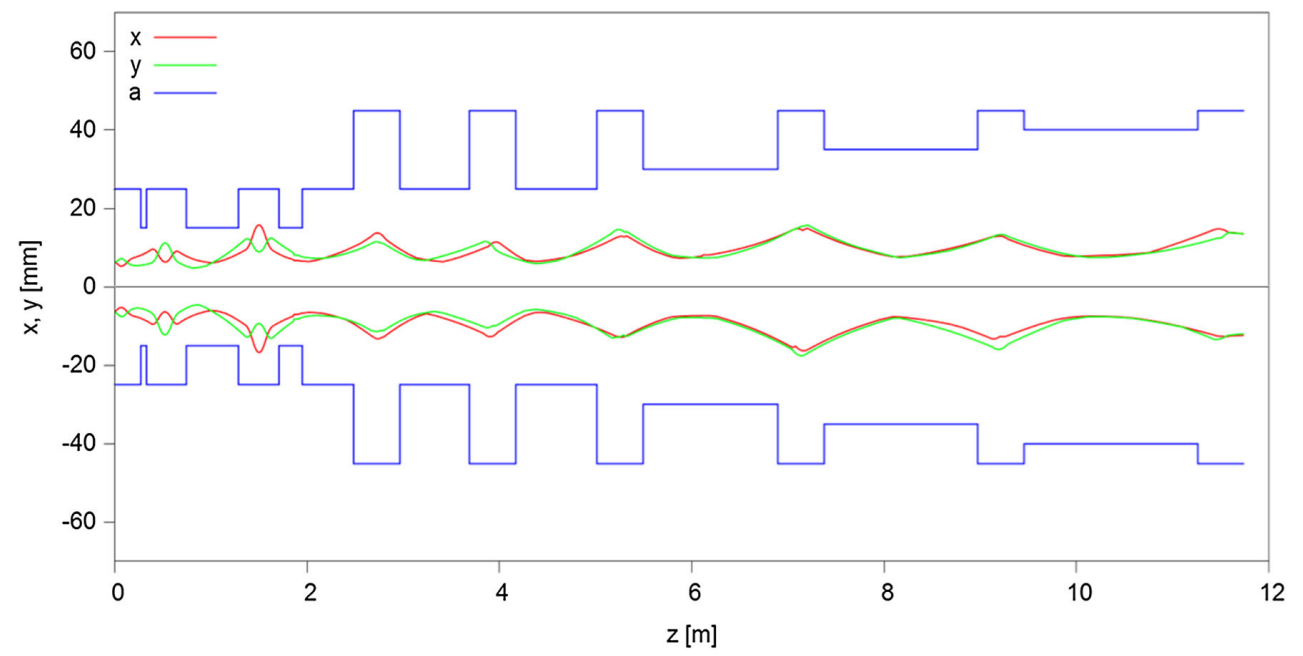

FIG. 12. Transverse $100 \%$ beam envelopes (all particles are included; red, $x$ plane; green, $y$ plane; blue, inner aperture of drift tubes or lenses).
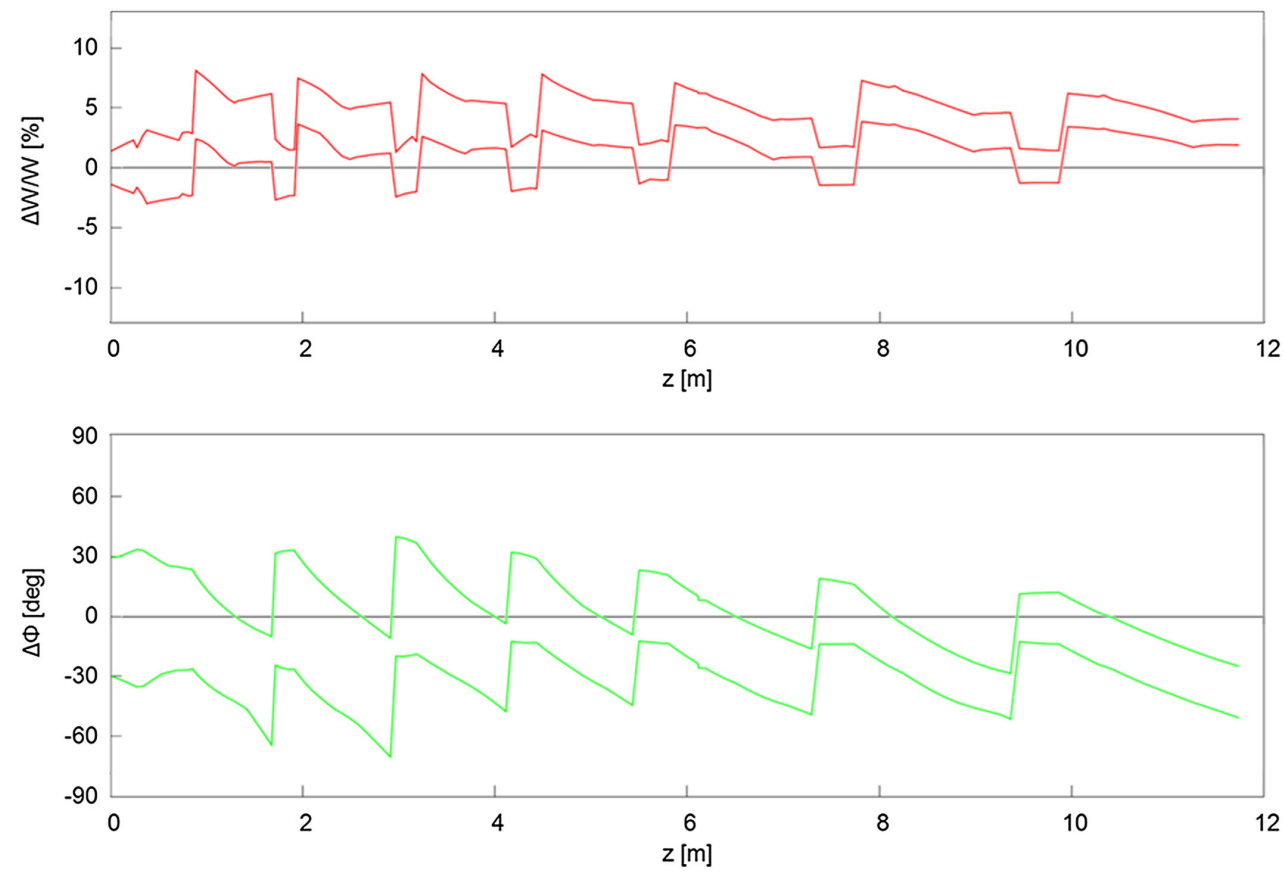

FIG. 13. Longitudinal 100\% beam envelopes (all particles are included; top, relative energy spread; bottom, phase spread).

\section{ERROR STUDIES}

For the design stage, only perfect accelerator components and ideal operating conditions have been taken into account. In reality, however, more or less perturbations to the design case are inevitable. Therefore, systematic studies have been done to check if the 6 MW DTL design is robust in the presence of various possible errors.

For the LORASR code, the following kinds of errors can be implemented [23,24]: transverse offsets of magnetic lenses (LOFF), rotations of magnetic lenses in all directions (LROT), voltage amplitude errors for accelerating cells and tanks (VERR), and phase errors for tanks (PERR).
Table III shows the three error settings applied to the 6 MW DTL design. From setting 1 to setting 3, the maximum errors have been increased accordingly. The error ranges in setting 3 have been deliberately made

TABLE III. Error ranges used for the three settings.

\begin{tabular}{lccc}
\hline \hline Error type & Setting 1 & Setting 2 & Setting 3 \\
\hline LOFF [mm] & \pm 0.1 & \pm 0.2 & \pm 0.3 \\
LROT [mrad] & \pm 1.0 & \pm 2.0 & \pm 3.0 \\
VERR [\%] & \pm 1.0 & \pm 2.0 & \pm 3.0 \\
PERR [ ${ }^{\circ}$ ] & \pm 1.0 & \pm 2.0 & \pm 3.0 \\
\hline \hline
\end{tabular}



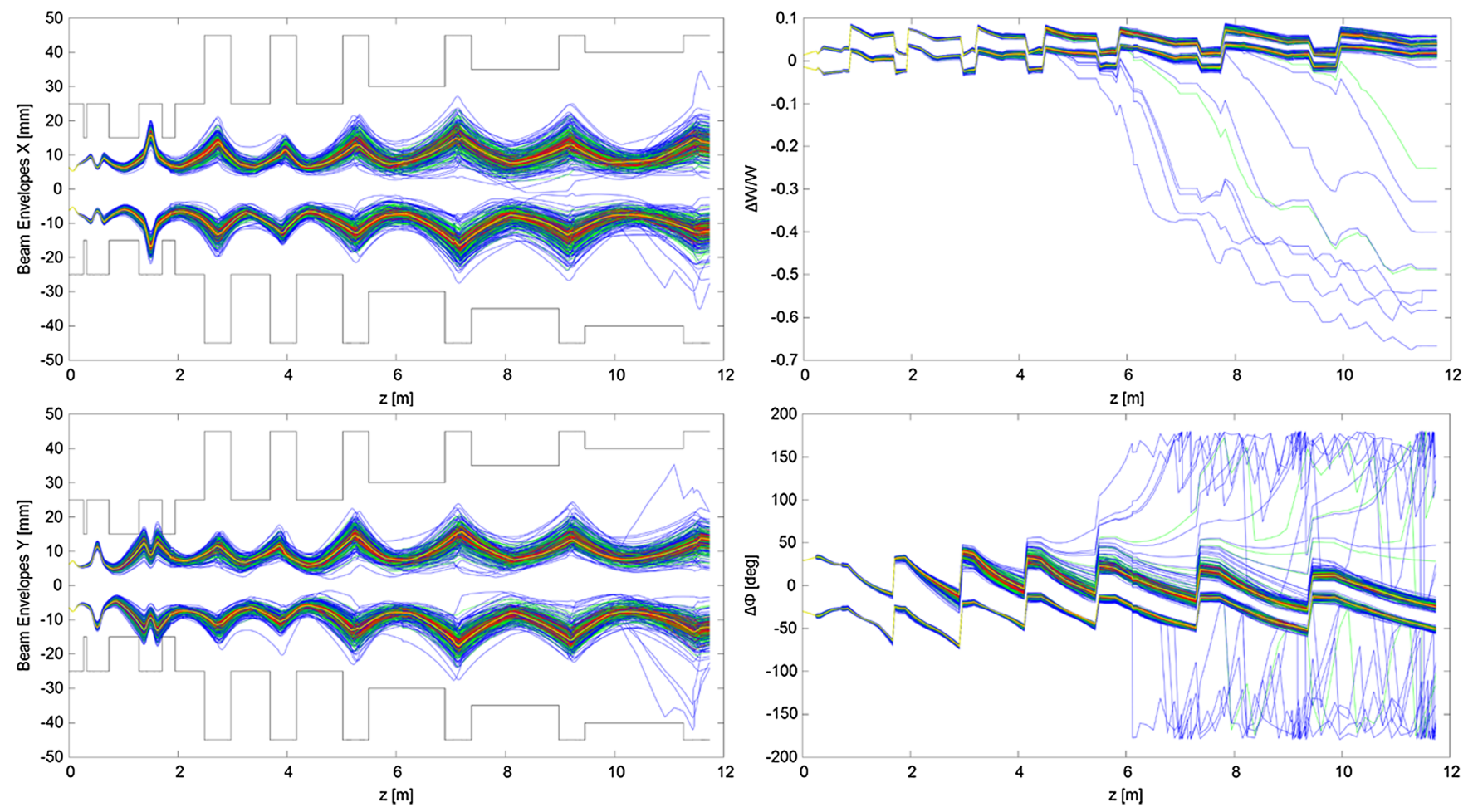

FIG. 14. Transverse (left graphs) and longitudinal (right graphs) 100\% beam envelopes (all particles are included) from all runs with errors (red, batch 1; green, batch 2; blue, batch 3).

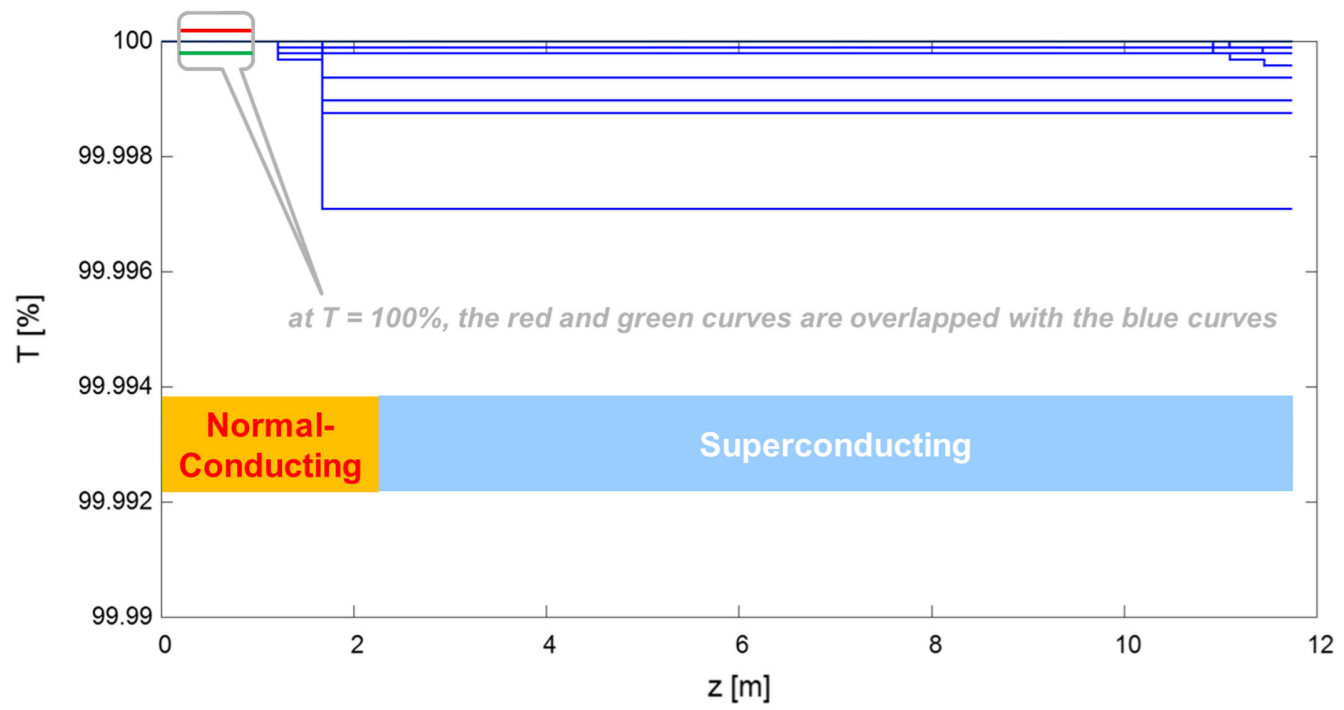

FIG. 15. Beam transmission efficiency evolutions for all runs with errors (red, batch 1; green, batch 2; blue, batch 3; because there is no beam loss for batch 1 and batch 2, only the blue curves can be seen).

bigger than the typical ones in order to see the "bottlenecks" of the linac.

To model various nonideal cases in the simulation, the above-mentioned errors have been generated randomly and mixed with each other. In LORASR, the randomly generated errors are Gaussian distributed and truncated at the maximum $A= \pm 2 \sigma_{d}$ with $\sigma_{d}$ being the standard deviation. For each error setting, a batch of 100 runs for different cases has been performed using $\sim 1$ million macroparticles. To see the influence of the errors, no steering correction is included in the simulations.

In Fig. 14, the transverse (see left graphs) and longitudinal (see right graphs) $100 \%$ beam envelopes of all 300 DTLs with errors are shown, in which the nominal 

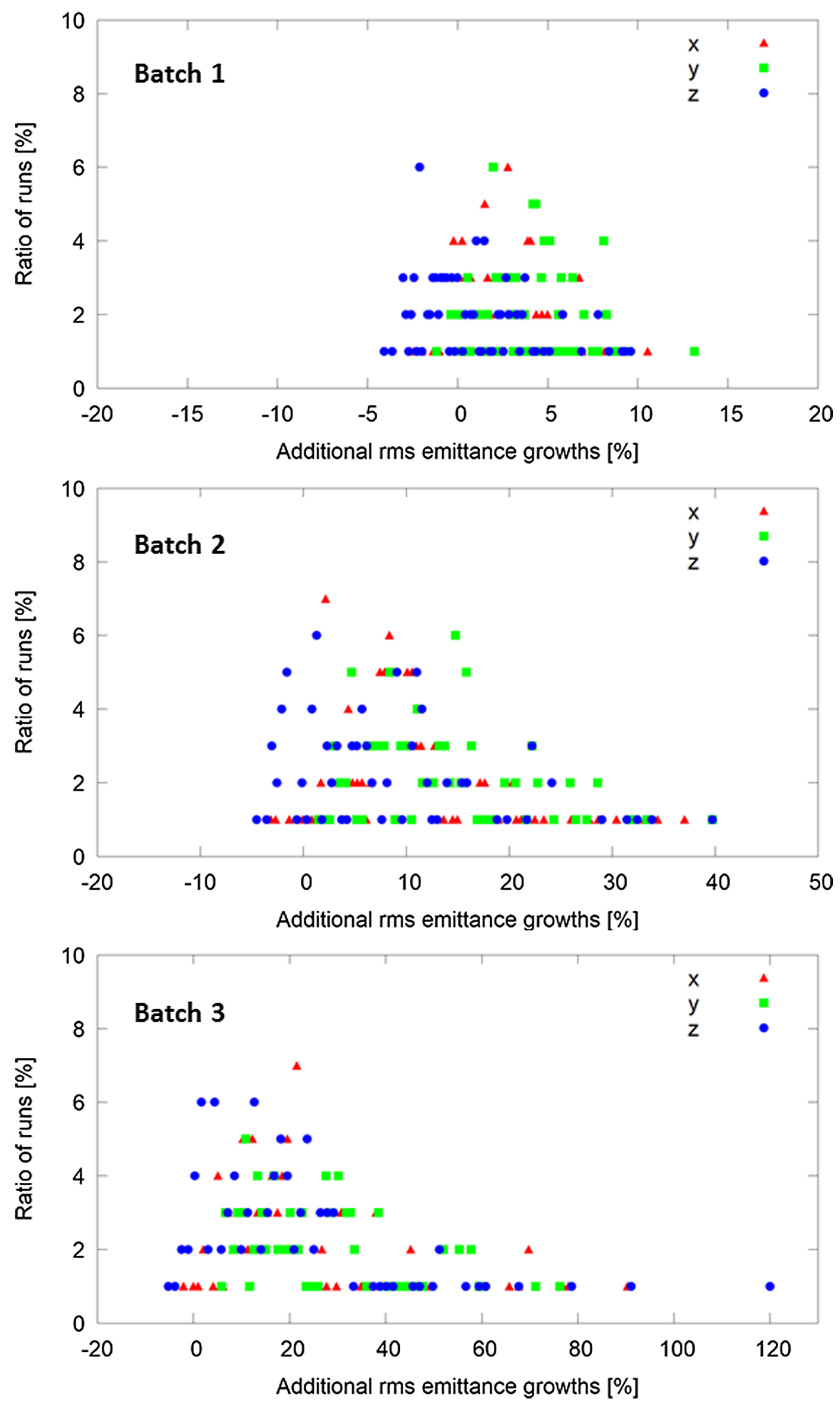

FIG. 16. Additional emittance growths induced by the errors (red, $x$ plane; green, $y$ plane; blue, $z$ plane).

case is marked in yellow for comparison. In batch 1, the transverse and longitudinal beam sizes have very limit deviations from the reference case. In batch 2 , only very few runs have produced some particles which start to leave the bunch longitudinally (see the green curves in the right graphs), but no particle touches the drift tubes or lenses (see the green curves in the left graphs), so there are still no beam losses. And, only in batch 3 , some beam losses have happened.

More clearly, one can see from Fig. 15 that (i) there are no beam loss for both batch 1 and batch 2 (the corresponding red and green curves are overlapped with the blue curves for 
batch 3 at $T=100 \%$ ) and (ii) only a few runs from batch 3 have drops in beam transmission efficiency, and the lowest value is still better than $99.997 \%$. Furthermore, most of these beam losses happened at the position $z=\sim 1.8 \mathrm{~m}$, where the second triplet locates (in the NC part).

As mentioned, the error ranges for batch 3 have been deliberately made bigger than the typical ones. Therefore, safe operation is expected for the 6 MW DTL if all errors can be well controlled within the typical ranges.

Figure 16 shows the statistics of the additional emittance growths induced by the mixed errors. The definition for the additional emittance growth is given as below:

$$
\Delta \varepsilon_{\text {addi }}=\frac{\varepsilon_{\text {out }}^{\text {with errors }}-\varepsilon_{\text {out }}^{\text {without error }}}{\varepsilon_{\text {in }}} .
$$

For batch 1 and batch 2, the maximum additional emittance growth is $\leq 40 \%$, while for batch $3, \Delta \varepsilon_{\text {addi }}$ is $\leq 95 \%$ and $\leq 120 \%$ in the transverse and longitudinal planes, respectively. A further particle tracking study proves that those large longitudinal additional growths are contributed by only a few off-energy particles. Therefore, the beam quality remains good in the presence of mixed errors.

\section{CONCLUSIONS}

In the past several decades, the combination of KONUS dynamics strategy and $\mathrm{NC} \mathrm{H}$-type structures has been developed as an efficient solution for accelerating low and medium $\beta$ beams. To address the challenges of very high intensity beams, a new idea to combine the KONUS dynamics with the recently developed SC CH structure has been proposed and investigated.

The investigation is based on a $150 \mathrm{~mA}, 6 \mathrm{MW}$ deuteron linac. To reach safe $\mathrm{CW}$ operation at such a very high intensity and mainly at $4.2 \mathrm{~K}$, a very careful design with conservative parameter choices (e.g., $E_{\text {a }}$ for the $\mathrm{SC} \mathrm{CH}$ cavities and starting $\Delta \phi$ and $\Delta W$ for the $0^{\circ}$ sections) and special optimization concepts (e.g., to add a $\mathrm{NC}$ transition section and to introduce super $0^{\circ}$ sections) has been made.

Because of the feature of the long lens-free sections allowed by the KONUS dynamics and the high accelerating gradient provided by the $\mathrm{SC} \mathrm{CH}$ structure, a very compact layout (only $\sim 12 \mathrm{~m}$ long) with a low number of accelerator components has been realized for the $150 \mathrm{~mA}, 6 \mathrm{MW}$ DTL. Detailed analyses show that the emittance transfer has been minimized and good beam quality has been achieved. In addition, benefitting from fewer components, the design shows also large tolerances against possible errors.

[1] R.W. Garnett, LANSCE accelerator update and future plans, J. Phys. Conf. Ser. 1021, 012001 (2018).

[2] N. Holtkamp, Status of the SNS linac: An overview, in Proceedings of LINAC2004, Lübeck, Germany (JACoW,
Geneva, 2004), p. 837, http://accelconf.web.cern.ch/ accelconf/104/papers/fr103.pdf.

[3] K. Hasegawa, Commissioning of the J-PARC Linac, in Proceedings of the 22nd Particle Accelerator Conference, PAC-2007, Albuquerque, NM (IEEE, New York, 2007), p. 2619, http://accelconf.web.cern.ch/accelconf/p07/papers/ thyab02.pdf.

[4] D. Vandeplassche, J.-L. Biarrotte, H. Klein, and H. Podlech, The MYRRHA linear accelerator, in Proceedings of the 2nd International Particle Accelerator Conference, San Sebastián, Spain (EPS-AG, Spain, 2011), p. 2718, http://accelconf.web.cern.ch/accelconf/ipac2011/papers/ weps090.pdf.

[5] A. Saini, Design considerations for the Fermilab PIP-II $800 \mathrm{MeV}$ superconducting linac, in Proceedings of NAPAC2016, Chicago, IL (JACoW, Geneva, 2016), p. 826, http://accelconf.web.cern.ch/accelconf/napac2016/ papers/wepoa60.pdf.

[6] H. Vernon Smith, Jr., J. D. Schneider and R. Sheffield, Low-energy demonstration accelerator (LEDA) test results and plans, in Proceedings of the 19th Particle Accelerator Conference, Chicago, IL, 2001 (IEEE, Piscataway, NJ, 2001), p. 3296, http://accelconf.web.cern.ch/accelconf/ p01/papers/rpph031.pdf.

[7] A. Ibarra, F. Arbeiter, D. Bernardi, W. Krolas, M. Cappelli, U. Fischer, R. Heidinger, F. Martin-Fuertes1, G. Micciché, A. Muñoz, F. S. Nitti, T. Pinna, A. Aiello, N. Bazin, N. Chauvin, S. Chel, G. Devanz, S. Gordeev, D. Regidor1, F. Schwab, and full IFMIF-DONES team, The European approach to the fusion-like neutron source: The IFMIF-DONES project, Nucl. Fusion 59, 065002 (2019).

[8] U. Ratzinger and R. Tiede, Status of the HIIF rf linac study based on H-mode cavities, Nucl. Instrum. Methods Phys. Res., Sect. A 415, 229 (1998).

[9] R. Tiede, U. Ratzinger, H. Podlech, and C. Zhang, KONUS beam dynamics designs using $H$-mode cavities, in Proceedings of HB2008, Nashville, Tennessee (JACoW, Geneva, 2008), p. 223, http://accelconf.web.cern.ch/ accelconf/hb2008/papers/wgb11.pdf.

[10] U. Ratzinger, E. Nolte, R. Geier, N. Gaertner, and H. Morinaga, The upgraded Munich Linear Heavy Ion Postaccelerator, Nucl. Instrum. Methods Phys. Res., Sect. A 263, 261 (1988).

[11] H. Podlech, U. Ratzinger, H. Klein, C. Commenda, H. Liebermann, and A. Sauer, Superconducting CH structure, Phys. Rev. Accel. Beams 10, 080101 (2007).

[12] R. Tiede, M. Heilmann, D. Mäder, O. Meusel, H. Podlech, U. Ratzinger, A. Schempp, and M. Schwarz, A coupled RFQ-IH-DTL cavity for FRANZ: A challenge for RF technology and beam dynamics, in Proceedings of HB2016, Malmö, Sweden (JACoW, Geneva, 2016), p. 404, http://accelconf.web.cern.ch/accelconf/hb2016/ papers/weam1y01.pdf.

[13] U. Ratzinger, Effiziente Hochfrequenz-Linearbeschleuniger für leichte und schwere Ionen, Habilitationsschrift (Goethe University, Frankfurt, Germany, 1998).

[14] W. Barth, K. Aulenbacher, M. Basten, M. Busch, F. Dziuba, V. Gettmann, M. Heilmann, T. Kürzeder, M. MiskiOglu, H. Podlech, A. Rubin, A. Schnase, M. Schwarz, 
and S. Yaramyshev, First heavy ion beam tests with a superconducting multigap $\mathrm{CH}$ cavity, Phys. Rev. Accel. Beams 21, 020102 (2018).

[15] S. Minaev, U. Ratzinger, H. Podlech, M. Busch, and W. Barth, Superconducting, energy variable heavy ion linac with constant $\beta$, multicell cavities of CH-type, Phys. Rev. Accel. Beams 12, 120101 (2009).

[16] F. Dziuba, M. Amberg, K. Aulenbacher, W. Barth, M. Basten, M. Busch, V. Gettmann, M. Heilmann, S. Mickat, M. Miski-Oglu, H. Podlech, M. Schwarz, and S. Yaramyshev, First cold tests of the superconducting cw demonstrator at GSI, in Proceedings of RuPAC2016, St. Petersburg, Russia (JACoW, Geneva, 2016), p. 83, http://accelconf.web.cern.ch/accelconf/rupac2016/papers/ wecbmh01.pdf.

[17] S. Belomestnykh, Review of high power CW couplers for superconducting cavities, in Proceedings of Workshop on High-Power Couplers for Superconducting Accelerators, Newport News, Virginia, USA, 2002, https://www.classe .cornell.edu/public/SRF/2002/SRF021105-09/SRF02110509.pdf.

[18] R. Tiede, G. Clemente, H. Podlech, U. Ratzinger, A. Sauer, and S. Minaev, LORASR code development, in Proceedings of the 10th European Particle Accelerator Conference, Edinburgh, Scotland, 2006 (EPS-AG,
Edinburgh, Scotland, 2006), p. 2194, http://accelconf .web.cern.ch/accelconf/e06/papers/wepch118.pdf.

[19] R. A. Jameson, RFQ designs and beam-loss distributions for IFMIF, Technical Report No. ORNL/TM-2007/001, Oak Ridge National Laboratory, 2007.

[20] A. Sauer, Untersuchungen zur teilchendynamik in hochstromlinearbeschleunigern für leichte ionen, Ph.D. thesis, Goethe University, Frankfurt, Germany, 2003.

[21] A. Kasugai et al., Commissioning status of linear IFMIF prototype accelerator (LIPAc), in Proceedings of HB2018, Daejeon, Korea (JACoW, Geneva, 2003), p. 2942, http:// accelconf.web.cern.ch/accelconf/hb2018/papers/thp1wb01 .pdf.

[22] M. Comunian and A. Pisent, Beam dynamics redesign of IFMIF-EVEDA RFQ for a larger input beam acceptance, in Proceedings of the 2nd International Particle Accelerator Conference, San Sebastián, Spain (EPS-AG, Spain, 2011), p. 670, http://accelconf.web.cern.ch/accelconf/ipac2011/ papers/mops031.pdf.

[23] R. Tiede, Description of the new machine error setting and analysis tools available for the LORASR beam dynamics code, IAP Internal Note No. IAP-DYNA-070807, 2007.

[24] R. Tiede, Description of the lens rotation error settings implemented to the LORASR beam dynamics code, IAP Internal Note No. IAP-DYNA-211107, 2007. 